\title{
Erratum to: Simplifying STOP-BANG: use of a simple questionnaire to screen for OSA in an Asian population
}

\author{
Thun How Ong • Siti Raudha $\cdot$ Stephanie Fook-Chong • \\ Nancy Lew • A. A. L. Hsu
}

Received: 30 December 2009/Revised: 31 March 2010/Accepted: 4 April 2010 / Published online: 8 June 2010

(C) Springer-Verlag 2010

\section{Erratum to: Sleep Breath}

\section{DOI 10.1007/s11325-010-0350-7}

Unfortunately, there are some errors in the article which need to be corrected, and we apologise for any confusion which we have caused. These are as follows:

\section{Table 2}

The number of patients who answered the questionnaire should read 319 ( rather than 314)

Under this column, the percentage of males who answered the questionnaires should be $69 \%$ (rather than $70.5 \%$ ) and the number of Chinese should be $76.4 \%$ (rather than $77.7 \%$ ).

(A transcription error of 314 instead of 319 resulted in the incorrect percentages of male and Chinese patients)

2. Abstract and Table 3

The values are for AHI $\geq 5, \geq 15, \geq 30$ ( instead of $>$ )

\section{Table 4}

The sensitivity of STOP-BANG for predicting AHI $\geq 15$ should read 91.3 (85.6-95.1) instead of 91.1

The online version of the original article can be found at http://dx.doi. org/10.1007/s11325-010-0350-7.

T. H. Ong $(\bowtie) \cdot$ S. Raudha $\cdot$ N. Lew $\cdot$ A. A. L. Hsu

Sleep Disorders Unit, Singapore General Hospital,

Outram Road,

Singapore 169608, Singapore

e-mail: ong.thun.how@sgh.com.sg

S. Fook-Chong

Department of Clinical Research, Singapore General Hospital,

Outram Road,

Singapore 169608, Singapore 